\title{
Bilateral Hypoglossal Nerve Injury with Occipital Condylar Fracture
}

\author{
Cornelius H. Lam and Joseph Stratford
}

\begin{abstract}
Background: A 20-year-old woman with a right occipital condylar fracture and bilateral hypoglossal nerve injury is presented. Only 17 cases of condylar fracture have been reported in the literature. Methods: The patient was evaluated with plain films, coronal and axial cut CT, and MRI. Results: MRI showed a severely distorted but otherwise normal medulla and a displaced condylar bone fragment. Conclusion: Condylar fracture may cause twelfth nerve palsy by injuring the central or peripheral nerve.
\end{abstract}

RÉSUMÉ: Lésion bilatérale du nerf hypoglosse lors d'une fracture du condyle occipital. Introduction: Nous présentons le cas d'une jeune femme de 20 ans qui s'est présentée avec une fracture du condyle occipital droit et une lésion bilatérale du nerf hypoglosse. Seulement 17 cas de fracture du condyle ont été rapportés dans la littérature. Méthodes: La patiente a été investiguée par radiographie simple, CT coronale et axiale et IRM. Résultats: On pensait antérieurement que la paralysie de l'hypoglosse était due a une lésion péripherique, distale par rapport au canal condylien antérieur. Chez ce patient, l'IRM a montré un bulbe rachidien très déformé mais normal par ailleurs. Conclusion: S'il y a fracture du condyle, la lésion du douziéme nerf peut être centrale ou périphérique.

Can. J. Neurol. Sci. 1996; 23: 145-000

Hypoglossal nerve injury occurs most often extra-axially, from tumors, Pagets disease, platybasia, carotid endarterectomy, anomalously high carotid bifurcation and viral infections. Rarely, the nerve has been injured in the cranium from vertical subluxation of the odontoid secondary to rheumatoid arthritis and trauma. ${ }^{1}$ One of the causes of traumatic twelfth nerve injury is occipital condylar fracture, which itself has been rarely documented. ${ }^{2-9}$ This case of cranial condylar fracture causing bilateral twelfth nerve injury has been followed for five years. The location, mechanism, and possible therapeutic implications of hypoglossal nerve injury from such a fracture are discussed.

\section{Case History}

This 20-year-old patient was a passenger, wearing a seat belt, in the front seat of a car. The car was hit on the side and overturned. On initial examination, she was found to be agitated with ecchymosis of the left cheek and unresponsive to painful stimuli on the right side. On arrival at the hospital, the patient was intubated, but was breathing spontaneously. She was noted to have a right clavicular fracture, right 11 th rib fracture, pulmonary contusion, and gross hematuria. Neurologically, the patient was unresponsive to commands, moving the left side spontaneously, moving her right arm sluggishly, and not moving her right leg. Pupils were equal and reactive to light, conjugate in gaze, and $5.5 \mathrm{~mm}$ in diameter. Fundi were normal, and the corneal reflex was present. No facial palsy was noted. Reflexes were symmetrical, except for an equivocal right Babinski response.

\section{Initial radiologic findings}

The lateral (Figure 1) and AP cervical spine $x$-rays were normal. The open mouth view was not performed. Plain CT of the head without posterior fossa cut demonstrated cerebral edema, with effacement of sulci, and small cisterns. No bony abnormalities were noted.

\section{Hospital Course}

On the first hospital day, the patient had a generalized seizure and was started on dilantin. She was able to be extubated the following day. She progressively recovered but was left with a right hemiparesis. She also had some difficulty talking, swallowing, protruding her tongue, and handling saliva. She denied any numbness of the face or extremities, diplopia, or difficulty in clenching her teeth.

On examination several weeks after injury, there was a paucity of tongue movements with atrophy of the lateral borders of the tongue, especially on the left. Her gag reflex was normal, and her palate elevated symmetrically. There was a right sided facial weakness of the central type. No weakness of the masseter, sternocleidomastoid or trapezius muscles was noted. On motor testing, she had a mild right sided weakness that was more pronounced distally. Sensory examination was normal. Deep tendon reflexes were brisk bilaterally but more so on the right side. The reflexes were pendular on the right side. She had a moderate to marked hypertonia on the right side and a mild dysmetria on the right upper extremity. Her gait was broadbased.

CT scan of the cranio-vertebral angle with contrast showed evidence of fracture of the right occipital condyle with displacement of a fracture fragment upwards and medially (Figure 2). This was best demonstrated by coronal imaging (Figure 3 ). Tomograms of the cranio-vertebral angle showed a fracture at the region of the right occipital condyle with a boney fragment displaced upwards and medially measuring 2 by $1 \mathrm{~cm}$. There was cranio-vertebral dislocation of $5 \mathrm{~mm}$ towards the right side.

On MRI, CSF spaces were prominent for the age of the patient (Figure 4). In the left cerebral peduncle, there was a punctate poorly defined area of increased signal intensity on the proton-density and the T2

From the Division of Neurosurgery, Montreal General Hospital, McGill University. Montreal.

RECEIVED FEBRUARY 28, 1995. ACCEPTED IN FINAL FORM JANUARY 4, 1996.

Reprint requests to: Joseph Stratford, M.D., Division of Neurosurgery, Montreal General Hospital, McGill University, 1650 Cedar Avenue, Montreal, Quebec, Canada H3G 1 A4 


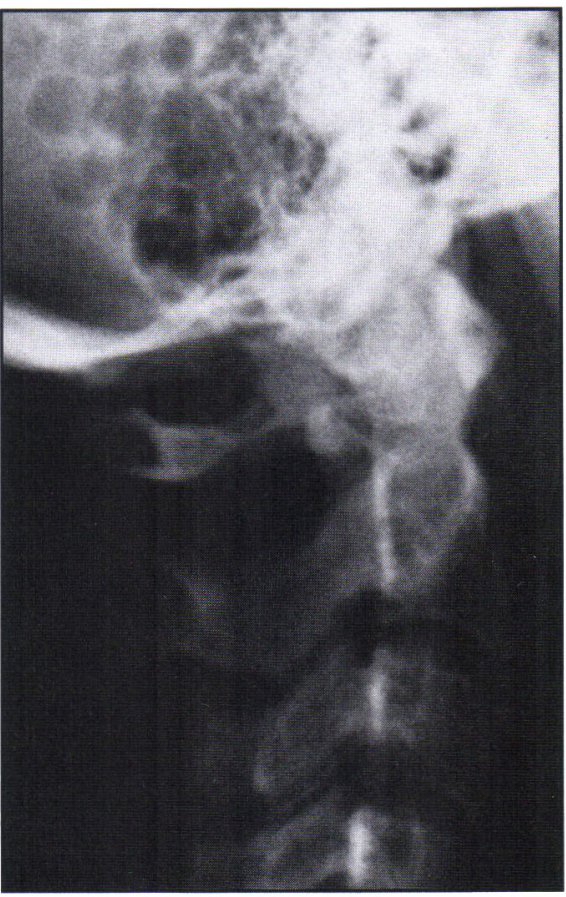

Figure 1: Lateral c-spine illustrating the difficulty in visualizing the craniovertebral junction on routine assessment. This plate appears normal.

weighted images. This cerebral peduncle abnormality likely represented a focal area of gliosis secondary to the patient's trauma that could account for the weakness in the patient's right side. There was evidence of mass effect on the medulla near the inferior margin of the clivus caused by a small linear area of signal void just to the right of midline seen on $\mathrm{T} 1$ weighted, T2 weighted, and proton density sequences. The bony fragment appeared to be situated in the premedullary cistern on the right side. This was causing compression and displacement of the anterior medulla to the left and posteriorly. The mass described in the pre-medullary cistern corresponded to a calcified density seen on the CT.

Because of the patient's improving clinical status and the difficult access to the craniovertebral junction, decompression of the medulla was not attempted. She was immobilized in a halo for three months without any deterioration in her neurologic status.

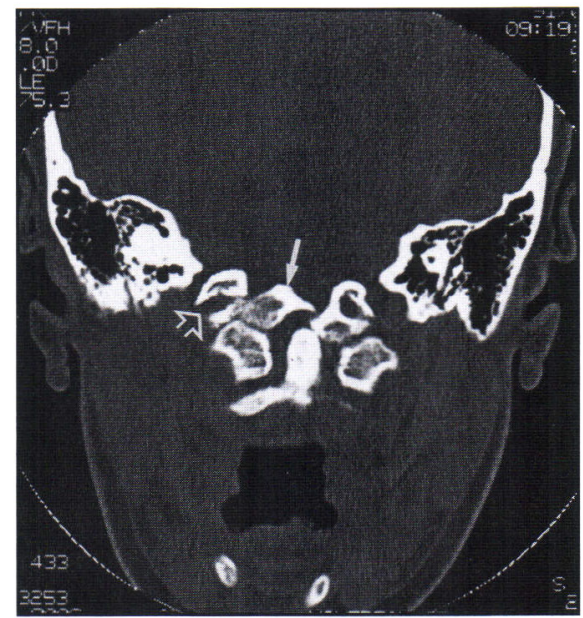

Figure 3: CT coronal section at the level of the odontoid demonstrates the upward and medial migration of the fracture fragment (white arrow). This fracture involves the jugular foramen (open white arrow).

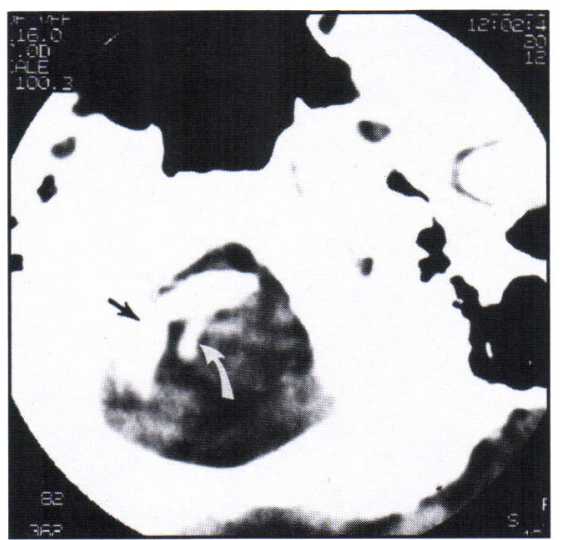

Figure 2: CT with contrast at the level of the foramen magnum. The banana shaped fragment is within the foramen (black arrow). The right vertebral artery is demonstrated by the white arrow.

Follow-up cervical spine $x$-rays on flexion extension showed no abnormality except some limitation of flexion. No angular or kyphotic abnormalities were seen.

With EMG, concentric needle examination of the right sternocleidomastoid muscle was normal. In both hypoglossal muscles, there were numerous positive wave and fibrillation potentials, and a moderate loss of motor unit potentials was activated on volitional movement. This was consistent with a bilateral hypoglossal neuropathy.

\section{Follow up course}

Two months after injury, the patient had a CT of the head which showed mild diffuse bilateral atrophy, but no focal lesions. One year later, she still had poor memory, slow rapid alternating movement, and weakness in the right thigh and arm. Dysarthria remained the same. After two years, the atrophy on the right side of the tongue was less, memory and the strength in her legs had improved. The right arm was mildly weak. Followup MRI at five years after injury shows the boney fragment remaining in the premedullary cistern and the displacement of the right hypoglossal nerve mainly at its origin from the medulla (Figure 5). The medulla itself does not show intrinsic abnormality despite high resolution examination of the posterior fossa. The left hypoglossal nerve could not be visualized, but clinically, the patient continued to have marked atrophy of the tongue.

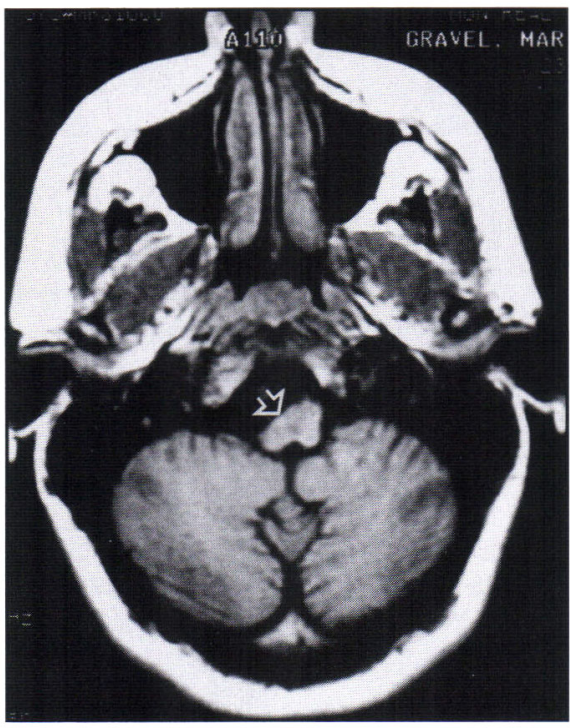

Figure 4: $T 1$ weighted axial MR imaging, demonstrates the distortions of the medulla (tip of open arrow) and of the anterior inferior cerebellar artery secondary to the boney fragment (under open arrow). 


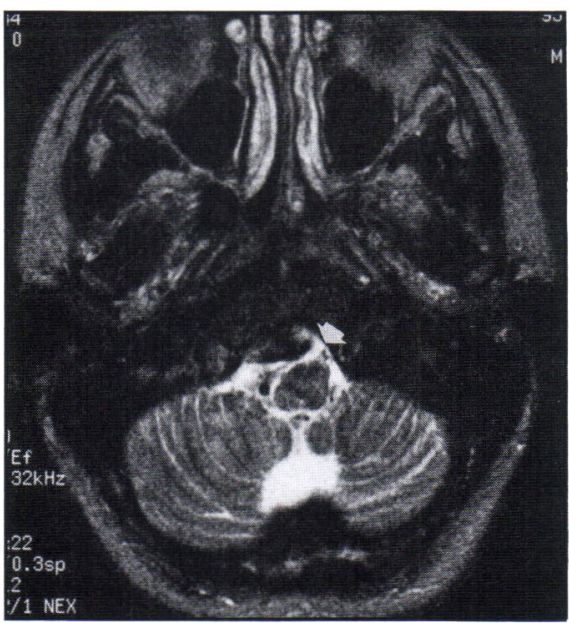

Figure 5: $T 2$ weighted axial MR imaging five years after injury. High resolution imaging demonstrates major nuclei and tracts in medulla. The hypoglossal nerve could be seen on the left (arrow) but not on the right.

\section{Discussion}

Intracranial injury to the twelfth nerve is rare. Carotid endarterectomy, high velocity and blunt trauma, $G$ forces from combat aircraft training, ${ }^{10}$ and viral infections appear to affect mainly the periphery of the nerve. This rarity could be due to the high mortality from brainstem injury which occurs if the intracranial portion of the nerve is also injured. Condylar fracture of the skull is also extremely rare. Spencer found 11 cases and added one more in $1984 . .^{9}$ There have been only five added to the literature since then, $3,6,8,11$ The central versus peripheral localization of injury has never been clear, and the mechanism of forces has never been discussed. We report a case of cranial condylar fracture with documented brainstem injury seen in MRI and a follow-up of five years.

Twelfth nerve injury is noted to be part of a combination of cranial injuries in condylar fracture such as the Sicard-Collet syndrome. ${ }^{6}$ As most fractures develop through the weakest portion in the bone such as at the jugular foramen, a peripheral injury could be invoked to explain the symptoms. A free fragment from these fractures seems to have the tendency to migrate upward and medially as could be seen in the radiographic images of other cases ${ }^{1,2,5.9}$ as well as this one. If a fragment moves a sufficent distance, central injury can result accounting for the bilaterality of the twelfth nerve symptoms, although with current MR technology, this could be difficult to ascertain.

The line of fracture permits the fragment to be pushed medially and upwards. This is probably secondary to the force vector directed by the angulation of the condylar facet. Jacob has noted that the fracture line runs laterally to the occipital condyle-jugular tubercle complex and can represent more extensive basilar fractures. ${ }^{6}$ Lateral flexion is also probably part of the injury, as a more axial load would cause the more common Jefferson burst fracture of $\mathrm{Cl}$.

The medulla occupies the unique location between the contents of the posterior fossa and spinal cord. Dohrman, Panjabi and Banks have pointed out the importance of considering forces of injury not only to the spinal cord, but also to the supporting structures in neuraxial injury, ${ }^{12}$ and this is probably the case for the medulla as well. Being tethered by the pontine structures above and the spinal cord below, and without direct supporting tissue otherwise, the medulla could sustain injuries secondary to unique biomechanical forces not yet completely understood.

After two years, the patient's twelfth nerve palsy is still worse on the left side compared to the right which is opposite to the side of the injury. Although the initial right hemiplegia was originally attributed to a punctate lesion in the midbrain, the patient could have suffered the syndrome of inferior alternating hemiplegia from a contre-coup injury. We could not demonstrate this on MR, and contre-coup injury to the brainstem has not been documented in the literature.

Most condylar fractures have been treated conservatively, with improvement or stability of the symptoms. This patient however had the added disadvantage of a free fragment with brainstem impingement. It was elected to observe conservatively the patient in an intensive care setting as her symptoms were stable. Surgical decompression could be argued for, especially with brainstem compression by the boney fragment. However, the patient's symptoms were not life threatening and she had stabilized during the immediate post-injury course. Had there been a degradation in the neurological status either from the boney fragment impingement or hematoma formation, decompression should have been done. Surgery would have entailed either a transoral or lateral approach with the risk of damaging local structures. ${ }^{9}$

After nine months of observation, the patient underwent careful flexion, extension, and rotational movements to check for stability. Clinically, the patient's twelfth nerve palsy did not worsen in the five years of follow-up. Delayed twelfth nerve palsy from trauma has been described and attributed to scar formation. ${ }^{8}$

In this case, initial plain CT did not show the fracture as standard cuts do not include the cranio-vertebral junction. It is recommended that CT scanning in this region be done if such an injury is suspected. Standard cervical spine films visualize the condylar/C-1 complex poorly. Tomograms were performed, but coronal $\mathrm{CT}$ with bone windows demonstrated the lesion the best. MRI demonstrated clearly the distortion of the brainstem and blood vessels.

Previous reports of condylar fractures, particularly with bilateral twelfth nerve palsy, are few. The pathophysiology of the injury is unclear. In this case, a peripheral injury is suspected given the extremely high resolution MRI scanning. A central injury is not completely ruled out given the amount of medullary distortion. The answer remains unclear without histologic analysis.

\section{REFERENCES}

1. Macedo TF, Gow PJ, Heap SW, Wallis WE. Bilateral hypoglossal nerve palsy due to vertical subluxation of the odontoid process in rheumatoid arthritis. Br J Rheumatol 1988; 27: 317-320.

2. Bolender N, Cromwell LD, Wendling L. Fracture of the occipital condyle. Am J Roentgenol 1978; 131: 729-731.

3. Delamont RS, Boyle RS. Traumatic hypoglossal nerve palsy. Clin Exp Neurol 1989; 26: 239-240.

4. Handel SF, Lee YY. Computed tomography of spinal fractures. Radiol Clin North Am 1981; 19: 69-89.

5. Harding-Smith J, MacIntosh PK, Sherbon KJ. Fracture of the occipital condyle. J Bone Joint Surg 1981; 63-A: 1170-1171. 
6. Hashimoto T, Watanabe O, Takase M, Koniyama J, Kobota M. Collet-Sicard syndrome after minor head trauma. Neurosurgery 1988; 23: 367-370.

7. Jacob CG. Fracture of the occipital condyle (letter). Am J Roentgenol 1979; 132: 500.

8. Orbay T, Sukru A, Zekai Z, Ergun R. Late hypoglossal nerve palsy following fracture of the occipital condyle. Surg Neurol 1989; 31: 402-404.

9. Spencer JA, Yeakley JW, Kaufman HH. Fracture of the occipital condyle. Neurosurgery 1984; 15: 101-103.
10. Katchen MS, Lyons TJ, Gillingham KK, Schlegel W. A case of left hypoglossal neurapraxia following $G$ exposure in a centrifuge. Aviat Space Environ Med 1990; 61: 837-839.

11. Wani MA, Tandon PN, Banerji AK, Bhatia R. Collet-Sicard syndrome resulting from closed head injury: case report. J Trauma 1991; 31: 1437-1439.

12. Dohrmann GJ, Panjabi MM, Banks D. Biomechanics of experimental spinal cord trauma. J Neurosurg 1978; 48: 993-1001. 